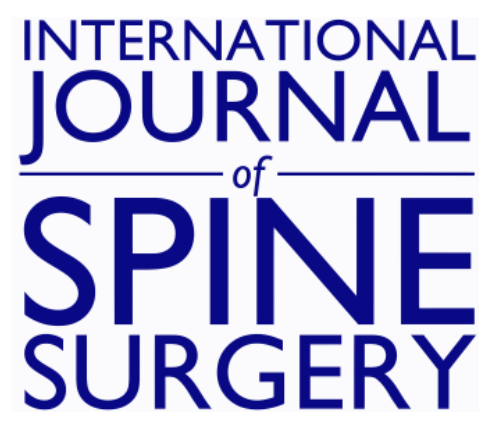

\title{
Unexplained Perioperative Vertebrobasilar Stroke in a Patient Undergoing Anterior Cervical Decompression and Disc Arthroplasty
}

Andrew James Berg, Cyrus Dokhanian Jensen, Richard Paul Jeavons, Guru Raj Reddy and Tai Freisem

Int J Spine Surg 2015, 9 ()

doi: https://doi.org/10.14444/2004

http://ijssurgery.com/content/9/4

This information is current as of April 26, 2023.

Email Alerts Receive free email-alerts when new articles cite this article. Sign up at:

http://ijssurgery.com/alerts

The International Journal of Spine Surgery

2397 Waterbury Circle, Suite 1,

Aurora, IL 60504, Phone: +1-630-375-1432 


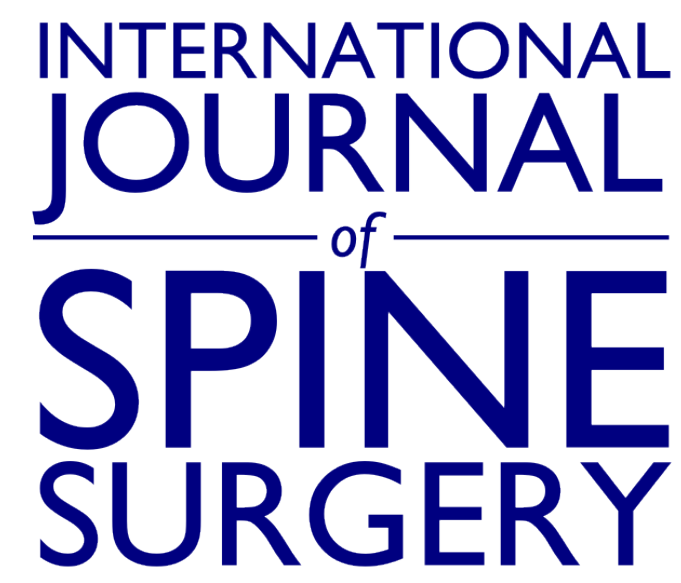

This article generously published free of charge by the International Society for the Advancement of Spine Surgery.

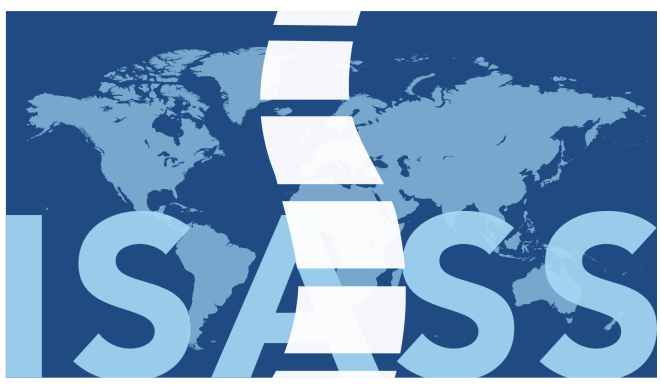

INTERNATIONAL SOCIETY for the ADVANCEMENT of SPINE SURGERY 


\section{Unexplained Perioperative Vertebrobasilar Stroke in a Patient Undergoing Anterior Cervical Decompression and Disc Arthroplasty}

Andrew James Berg, MRCS, ${ }^{1,2}$ Cyrus Dokhanian Jensen, FRCS, ${ }^{1}$ Richard Paul Jeavons, FRCS, ${ }^{1}$ Guru Raj Reddy, MBBS, ${ }^{l}$ Tai Freisem, $M D^{1}$

${ }^{1}$ North Tees and Hartlepool NHS Foundation Trust, ${ }^{2}$ Pennine Acute Hospitals NHS Trust

\section{Abstract}

\section{Background}

Vertebrobasilar stroke associated with the anterior approach to the cervical spine is rare and has not been reported in cervical disc arthroplasty surgery. We report the case of a 60-year-old patient who underwent cervical disc arthroplasty at C4-5, C5-6 and C6-7. Postoperatively, due to symptoms and signs of a cerebellar stroke, magnetic resonance imaging of the brain was obtained confirming this diagnosis. Despite thorough investigation no specific identifiable cause for the stroke has been identified. We hypothesis an unrecognised period of intraoperative hypotension may have caused a temporary reduction in vertebrobasilar blood flow.

\section{Methods}

A retrospective review of the patient's case notes and a focused review of literature has been performed.

\section{Results}

Now two years postoperatively the patient has regained full power but has residual problems with balance. She has neuralgic pain down the right side of her body which following investigation is believed to result from the stroke.

\section{Conclusions / Level of Evidence}

Surgeons should be aware vertebrobasilar stroke is a possible rare perioperative complication associated with anterior cervical decompression and disc arthroplasty. Level V.

keywords: cervical arthroplasty, Anterior Cervical Decompression, disc replacement, Vertebrobasilar, Stroke, Complication 


\section{Introduction}

The anterior approach to the cervical spine is commonly used for the surgical treatment of degenerative cervical disc disease.

Complications involving the vertebral arteries are recognised but rare. ${ }^{1-6}$ These include intra-operative haemorrhage, late-onset haemorrhage, arteriovenous fistulae, pseudoaneurysm, dissection, partial or complete thrombosis, embolic events, cerebral ischemia, stroke and death. ${ }^{7}$ These complications may result from direct trauma, compression or traction of the vertebral arteries during surgery. Complications may become evident with intraoperative or postoperative haemorrhage or with abnormal postoperative neurological signs or symptoms and confirmed with vascular and cerebral imaging.

To our knowledge no other cases of vertebrobasilar stroke, associated with anterior cervical decompression and disc arthroplasty, have been reported. Further to this, all other reports of vertebral artery complications, which we identified in the literature, have been able to directly associate a cause for the complication. In the case we report, despite extensive investigation, no specific cause for the complications has been identified.

\section{Case Report}

A 60-year-old female presented with worsening radiculopathy in the right C5, C6 and C7 dermatomal distributions. She had no motor deficit or signs of myelopathy. Magnetic resonance imaging (MRI) showed foraminal stenosis and focal cord compression at corresponding levels. The patient was offered and consented to surgery in the form of anterior cervical decompression and disc arthroplasty at C4-5, C5-6 and C6-7.

She attended for anaesthetic pre-operative assessment several weeks prior to surgery. A history of controlled hypertension with a sitting blood pressure of $130 / 80 \mathrm{mmHg}$ in clinic was noted. Her body mass index was 22 . She was a non-smoker and had normal serum cholesterol levels.

She underwent elective C4-5, C5-6 and C6-7 anterior cervical decompression and disc arthroplasty using NuNec (Pioneer Surgical, Marquette, MI) prostheses (Figure 1). Surgery was performed in a standard manner using a right-sided anterior retropharangeal approach. Of note her neck was maintained in a neutral position with her head positioned on a head ring and taped securely in position. Over distraction of the vertebral bodies was also not utilised for implant insertion. General anaesthetic was uncomplicated and intraoperative haemorrhage was well controlled with a total blood loss of 200 millilitres. Invasive blood pressure monitoring was not used. The documented intermittent noninvasive systolic blood pressure did not fall below $90 \mathrm{mmHg}$ throughout the procedure. 


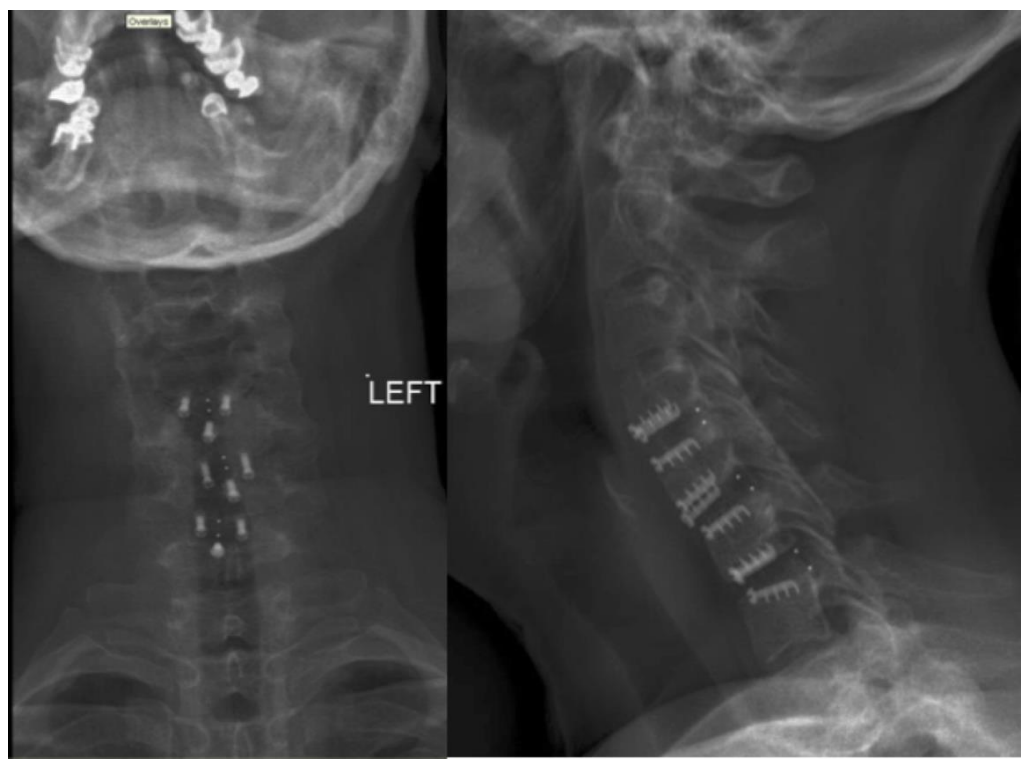

Fig. 1. Postoperative anteroposterior and lateral radiographs showing cervical disc arthroplasty implants at C4-5, C5-6 and C6-7.

When the patient had adequately regained consciousness from anaesthesia she complained of a headache, diplopia and left sided weakness. On examination she was found to have 3/5 power on the Medical Research Council scale 8 in the left arm and leg. Given these symptoms an urgent MRI of the brain and cervical spine were obtained. A large left inferior cerebellar signal abnormality indicating a cerebellar infarct or ischemia with some abnormal signal in the adjacent brainstem was found (Figure 2). MRI imaging of the cervical spine showed satisfactory decompression of the cord and foramina and no changes in the cord itself. Subsequently carotid and vertebral artery angiography and carotid doppler examinations were performed and were reported by the radiologists as showing patent carotid and vertebral vessels with no structural abnormalities and a patent Circle of Willis (Figure 3). Transthoracic cardiac echocardiogram did not reveal any thrombus. 


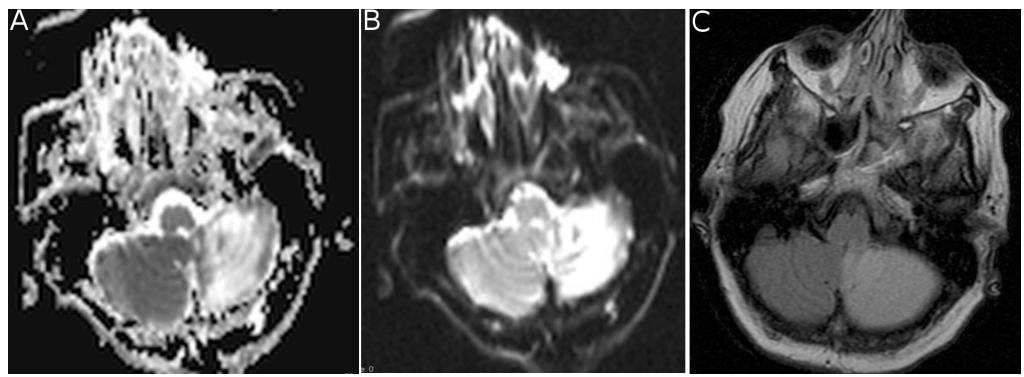

Fig. 2. Postoperative MRI brain showing left inferior cerebellar signal abnormality indicating infarction or ischemia. A: Apparent diffusion coefficient MRI. B: Diffusion MRI. C: Axial T2 flair MRI image.

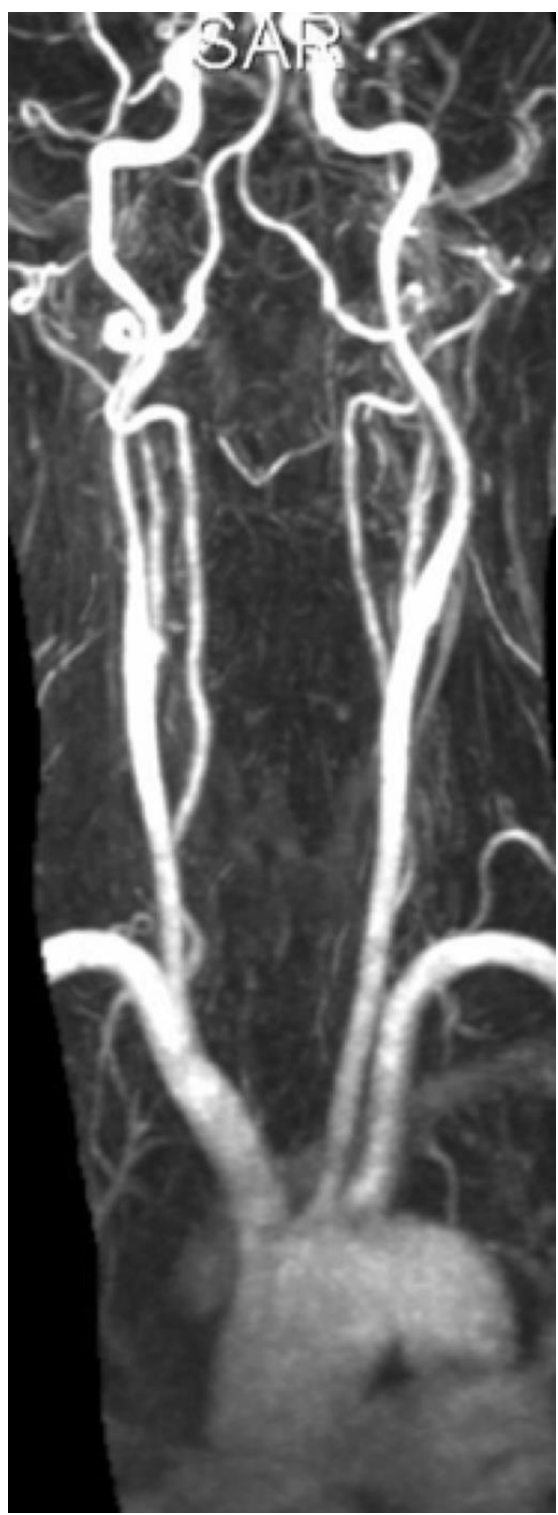

Fig. 3. MRI angiography displaying no structural abnormality with patent carotid vessels and patent Circle of Willis. 
The patient was transferred to the stroke rehabilitation ward where her condition improved with physiotherapy and she was discharged home twelve days postoperatively. She was initially followed-up as an outpatient by the stroke team but has now been discharged from their care. The patient is now two years following surgery. She has regained full power but has residual problems with balance, mobilising with one stick. More significantly for the patient, she has suffered from neuralgic pain down the whole right side of her body throughout follow-up despite analgesics. The cause of this pain has been investigated with MRI imaging of the whole spine and brain and electromyography studies. No neural compression has been identified and the intracerebral changes have not progressed. We therefore hypothesise that her symptoms are a consequence of the stroke sustained at the time of surgery.

\section{Discussion}

Vertebrobasilar stroke following anterior cervical decompression and disc arthroplasty is an unreported complication. While the risk of complications involving the vertebral arteries is more likely related to the approach and decompression rather than the implant used we feel the risk of occlusion of the vertebrobasilar vessels is likely to be lower with arthroplasty than fusion as will be discussed further.

The reported incidence of vertebral artery complications associated with other anterior cervical procedures is $0.3-0.5 \%{ }^{1,5}$ Most reported cases are a result of direct operative trauma with increased risk linked to tortuous vertebral arteries or far lateral bone removal. ${ }^{1,4}$ There are, however, a few cases where no direct trauma has been reported.

Vertebral artery dissection resulting in posterior circulatory stroke has been reported after cervical corpectomy. In the absence of surgical trauma the authors hypothesise that cervical traction may be implicated. ${ }^{9}$

A further case reports a large ischaemic brain stem stroke in a previously asymptomatic patient while undergoing C5-C6 discectomy for infection. The authors implicate basilar artery occlusion based on the findings of brain computer tomography. The authors hypothesize that the prolonged neck hyperextension that they employed in addition to the surgical manipulation of a severely inflamed vertebral system may have contributed to the aetiology of the occlusion. ${ }^{10}$

In contrast to cervical fusions where neck hyperextension may be utilised, in cervical disc arthroplasty surgery the neck is maintained in a neutral position. Our standard surgical procedure, in patients undergoing cervical arthroplasty, is to secure the neck in a neutral position. This is done with the head positioned on a head-ring and taped securely in position. This procedure was adhered to in the reported case. We therefore feel it is unlikely that an occlusion of the vertebral vessels has been caused by hyperextension or rotation of the cervical spine.

There was no traction applied during the procedure and over distraction of the vertebral bodies was not required due to the cam lock design of the NuNec disc prosthesis.

Postoperative imaging did not show any vessel abnormality consistent with surgical trauma or pre-existing arterial disease. There was no evidence of an embolic source. 
The only cardiovascular risk factor, in the patient was hypertension, which was controlled with antihypertensive medications. This may have contributed in this case, however, as her cerebral blood flow autoregulatory curve may have shifted upwards rendering her more at risk for reduced blood flow during episodes of hypotension than a normotensive patient. According to the anaesthetic documentation the systolic blood pressure was maintained above $90 \mathrm{mmHg}$ intraoperatively.

The precise cause of the patient's stroke therefore remains unexplained. Given the lack of a structural injury or occlusion of the vertebral arteries there may have been a temporary lack of vertebrobasilar blood flow. We hypothesise this may have been due to an unrecognised intraoperative hypotensive episode. This case serves to demonstrate to other surgeons, that despite precautions, a vertebrobasilar stroke is a possible rare perioperative complication associated with anterior cervical decompression and disc arthroplasty.

\section{References}

1. Burke JP, Gerszten PC, Welch WC. Iatrogenic vertebral artery injury during anterior cervical spine surgery. Spine J. 2005 Sep;5(5):508-14-discussion514.

2. Peng CW, Chou BT, Bendo JA, Spivak JM. Vertebral artery injury in cervical spine surgery: anatomical considerations, management, and preventive measures. Spine J. 2009 Jan;9(1):70-6.

3. Daniels AHA, Riew KDK, Yoo JUJ, Ching AA, Birchard KRK, Kranenburg AJA, et al. Adverse events associated with anterior cervical spine surgery. J Am Acad Orthop Surg. 2008 Dec 1;16(12):729-38.

4. Daentzer D, Deinsberger W, Böker D-K. Vertebral artery complications in anterior approaches to the cervical spine: report of two cases and review of literature. Surg Neurol. 2003 Apr;59(4):300-9-discussion309.

5. Smith MD, Emery SE, Dudley A, Murray KJ, Leventhal M. Vertebral artery injury during anterior decompression of the cervical spine. A retrospective review of ten patients. J Bone Joint Surg Br. 1993 May;75(3):410-5.

6. Wang MC, Chan L, Maiman DJ, Kreuter W, Deyo RA. Complications and mortality associated with cervical spine surgery for degenerative disease in the United States. Spine. 2007 Feb 1;32(3):342-7.

7. Tang S-J, Rao RD. Perioperative and Approach-Related Complications Associated with Anterior Cervical Surgery. Seminars in Spine Surgery. 2009 Sep;21(3):148-55.

8. Medical Research Council (1981). Aids to the examination of theperipheral nervous system. Memorandum No. 45. Her Majesty's Stationary Office, London.

9. Dickerman RD, Zigler JE. Atraumatic vertebral artery dissection after cervical corpectomy: a traction injury? Spine. LWW; 2005;30(21):E658- 661.

10. Tsai Y-F, Doufas AG, Huang C-S, Liou F-C, Lin C-M. Postoperative coma in a patient with complete basilar syndrome after anterior cervical discectomy. Can J Anaesth. 2006 Feb;53(2):202-7.

\section{Disclosures}

Tai Friesem is a consultant for RTI Surgical and Globus Medical. The other authors declare no disclosures. 


\section{Corresponding Author}

Mr Andrew Berg, MRCS, Spinal Unit, University Hospital of North Tees, Hardwick,

Stockton on Tees, TS 19 8PE. a.j.berg@doctors.org.uk.

Published 17 February 2015.

Copyright (C) 2015 ISASS - International Society for the Advancement of Spine Surgery.

To see more or order reprints or permissions, see http://ijssurgery.com. 